\title{
Analysis of the Process in Brief Psychotherapy Group: The Role of Therapeutic Factors
}

\author{
Cristina Marogna ${ }^{1} \&$ Floriana Caccamo $^{1 \bowtie}$
}

\begin{abstract}
In all group therapeutic processes, there are interacting and interdependent mechanisms and changing conditions: the therapeutic factors (Corsini \& Rosenberg, 1955; Yalom, 1995). These factors are intrinsic to the therapeutic process and unrelated to the type of group (Rorhbaugh \& Bartels, 1975). The present study examines the factor structure of the questionnaire Factors Aspecific and Specific in the Group Therapy (FAT.A.S.-G.; Marogna, 2009), designed to investigate specific and non-specific therapeutic factors. The questionnaire was administered to 167 patients involved in a shortterm psychotherapy group. The factor analysis identified two main dimensions: interdependence and the group as Object-Self. The Cronbach Alpha coefficients range from .88 to .93 , showing high internal consistency between items.
\end{abstract}

Keywords: therapeutic process, therapeutic factors, interdependence, group as Object-Self

In group psychotherapy, the term "process" refers to the nature of the relationship between interacting individuals, members, therapists, and the related meta-communicative aspects (Leszcz \& Yalom, 2005; Lis et al., 2010). Considering the therapeutic process, therefore, should be take into account different factors, such as the inner psychological worlds of each individual and the interactions and strengths of the entire group (Brown \& Barlow, 1995; Ettin, 1999). The international literature has highlighted that all group therapeutic processes present interacting and interdependently changing mechanisms and conditions: the therapeutic factors (Corsini \& Rosenberg, 1955; Yalom, 1995). These factors are intrinsic to the therapeutic process, are unrelated with the type of group, and strengthen each other and the achievement of one promotes the occurrence of the other two (Rorhbaugh \& Bartels, 1975). Several authors have stated that the therapeutic factors contribute to patients' relational and symptomatic progresses, which are related to

\footnotetext{
${ }^{1}$ Department of Philosophy, Sociology, Pedagogy and Applied Psychology (FISSPA), Padua, Italy.

Correspondence concerning this article should be addressed to Floriana Caccamo. Dipartimento di Filosofia, Sociologia, Pedagogia e Psicologia Applicata, Università di Padova, Via Venezia, 8.E-mail: florianacaccamo@virgilio.it.
}

the interventions both of the therapist and other members of the entire group that also includes patients (Bloch \& Crouch, 1985; MacKenzie, 1981).

Yalom (1995) identified 11 therapeutic factors: 1. Infusion of hope (In a mixed group characterized by people at various development or recovery stages, some members could be inspired to encourage others to cope with the problems they are still struggling with); 2 . Universality (The recognition of shared experiences, feelings, and universal human concerns among group members helps to remove the sense of isolation, to validate their experiences, and to raise their self-esteem); 3. Information/guidance (Despite this fact not being strictly related with the psychotherapeutic process, members often report that it is very helpful to learn information from other members in the group, such as that regarding treatment or access to the services); 4. Altruism (The group is a place where members can help each other, and the experience of being able to give something to another person can reinforcement the members' self-esteem and help them to develop more adaptive coping styles and interpersonal skills); 5. Corrective recapitulation of the primary family group (Members often unconsciously identify the group therapist and other group members with their own parents and siblings in a process that is a form of group psychotherapy- 
specific transference. The therapist's interpretations can help group members to understand the impact of childhood experiences on their personality and to learn how to avoid unconsciously repeating unhelpful past interactive patterns in presentday relationships); 6. Socializing techniques (The group setting provides a safe and supportive environment for members to extend their repertoire of interpersonal behavior and improve their social skills), 7. Imitative behavior (The modeling process is a way in which group members can develop social skills by observing and imitating the therapist and other group members. such as in sharing personal feelings, showing concern, and supporting others); 8. Interpersonal learning (Group members achieve a greater level of self-awareness interacting with others in the group and this give feedback on members' behavior); 9. Cohesion (This is the primary therapeutic factor from which all others flow. $\mathrm{Hu}$ mans are herd animals with an instinctive need to belong to groups, and personal development can only take place in an interpersonal context. A cohesive group is one in which all members feel a sense of belonging, acceptance, and validation); 10 . Catharsis (This is the experience of relief from emotional distress through the free and uninhibited expression of emotions. When members tell their story to a supportive audience, they can obtain relief from chronic feelings of shame and guilt); and 11. Existential factors (The awareness of life responsibility and the consequences of one's decisions).

Regarding the complexity of the phenomena that occur in intra- and interpsychic groups, it is difficult to identify an absolute hierarchy of therapeutic aspects and, for this reason, the therapeutic factors are differentiated on the basis of different dimensions such as the state of patient regression, the conducting procedures, and the length and the development stage of the group (Butler \& Fuhriman, 1983; Roy, Turcotte, Montminy, \& Lindsay, 2005; Yalom, 1975). The only existing hierarchy was made by Parloff and colleagues (1988) who attempted to categorize non-specific and specific factors: the first are not related to a theoretical model or the specific technique used by the therapist and the second, conversely, are related to a specific therapeutic model and strategies derived from it (Parloff, 1988).

The intrinsic factors of the therapeutic process are derived from the particular factual and procedural group setting such as multi-personal relationships, differences in specific psychic fields, and the importance of nonverbal communication. These aspects characterize the intersubjective exchange that takes place in a therapeutic group within which most people are in relationship; sharing experiences and developing empathetic feelings contribute to creating a relationship that supports the group (Kivlighan \& Goldfine, 1996).
Intersubjectivity provides fundamental elements to understand the therapeutic process in group psychotherapy, and it promotes the group formation, increases its functioning, and ensures its cohesion (Stern, 2005). In the group, the intersubjective dimension promotes mentalization, which is the ability to think about themselves and others in terms of mental states, both implicit and explicit (Fonagy, Gergely, Jurist, \& Target, 2002). Intersubjectivity is constituted by the encounter, in various combinations, of the subjectivity of all members group including the therapist. The global manifestation of the group is conveyed to the concept of "Self of group," which brings together the projects, ambitions, and ideals of a particular therapeutic community. This group image implies a great deal of attention to the ability of all members to take an empathetic position (Harwood \& Pines, 1998). The group can facilitate new internalizations that encourage therapeutic change, promoted not only by the discovery of a new meaning to the verbal level but also by the possibility of new and different experiences of regulations with respect to a particular mental content (Orange, Atwood, \& Stolorow, 1999). This is in accordance with Bion (1977), who asserted that individual, interpersonal, and group therapeutic processes work on the principle of container-contained (Di Riso, et al., 2011; Ogden, 2004). This is a model of a group based on the relational mechanism of projective identification, is essential for the ability to group-reverie, and allows the attribution of meaning to the emotions without meaning (Bion, 1972).

The reverie is a function with a detoxifying capacity to promote positive changes because the therapist can recognize the individuals' needs and the group can be thought (Bion, 1972). This feature, known as the Alpha Function, is linked to the ability of the analyst to incorporate the patient's preverbal or verbal communications with concurrent processing tasks (Corrao, 1981). The reverie originally has a relational function, as it is the core of the mentalization process that allows someone to sort and harmonize the scattered elements contributing to the discovery of meanings and thus the capacity for thought. The group therapeutic process, triggering the phenomena of reflection, circularity, and tuning, helps to create a shared and multi-dimensional mental space in which the others, in the space of the group, are potential mirrors reflecting emotional content, positives, and negatives that refer to the individual as an image of the impressions that stimulated him or her (Foulkes, 1975).

Today, group psychotherapy relies on a solid empirical foundation for the effectiveness of treatments, yet despite this relatively few studies have investigated the therapeutic process for groups.

This is due both to the lack of specific instruments to assess the elements of processuality of the 
group both in the multiplicity of the relational group setting, which makes it hard to analyze (Burlingame, MacKenzie, \& Strauss, 2004; Joyce, McNair-Semands, Tasca, Ogrodniczuk, 2011; Kirchmann et al., 2009; Kivlighan \& Kivlighan, 2004; McNair-Semands, Ogrodniczuk, Joyce, 2010).

As regards research on the group process, Beck and Lewis (2000) emphasize the importance of studying the group system as a whole and highlighted the importance of changes that occur in the course of its development and in the interactions between the subsystems, therapist, and patient. Considering the work of Bednar and Kaul (1994), future studies should study more precisely the measures of the elements of the group to advance research and clinical practice.

The present study, by referring to the current panorama of research on the process of group psychotherapy, has the aim to contribute to study factorial structure and contribute to the validation of FAT.A.S.-G.

As stated by Yalom (2005), the distinctions between factors are arbitrary and they do not work separately. This finding suggests the usefulness of identifying a superior order of the factors by studying how the group process can be influenced by complex and interrelated factors that capture more significance (Kivlinghan \& Lilly, 1997; McGrath, 1997). The overlap between the factors does not mean that they are less significant, but that some, if taken separately and disconnected from others, are less relevant and may also represent a specific aspect of a global therapeutic higher order factor (Fuhriman, 1986; Lese \& MacNair-Semands, 2000; Tschuschke, Dies, 1994).

Different measures were built to assess changes in group psychotherapy by analyzing specific and aspecific factors, and unfortunately many of these presented relevant limitations. One of these is the GrEThA-Q (Giorgi, Sguazzin, Baiardi, Simone, \& Tesio, 2006), built on the basis of Yalom's theory (1995), that is structured as 15 items that the participants answer using a true or false scale. It is quick and easy to administrate and useful for repeated evaluations, but it is characterized by substantial structural and conceptual limitations and does not present solid psychometric requirements. The instrument does not describe which therapeutic factor every single item investigates. In addition, the true-false response scale appears inadequate in effectively evaluating if the intensity of the variables is changes significantly during the therapeutic process, which is the crucial element for assessing the progress of the therapeutic process.

The Group Climate Questionnaire-Short Form (CGQ-S; Mackenzie, 1981) is a measure of the therapeutic process and consists of 12 items measured on a 6-point Likert scale. It assesses the climate existing between the members of a group through three scales: involvement, conflict, and avoidance.
The results are shown as average scores for each subscale item (Table 1). The questionnaire can be filled in by patients, therapists, or observers at the end of a group session. An Italian version of this measure (Costantini, Picardi, Podrasky, Bezel, \& Ferrara, 2002) was used in this study to identify some constructs of the analyzed group. The measure, however, has limited scale and is not attributable to a substantial proportion of therapeutic factors.

The California Psychotherapy Alliance Scale (CALPAS; Gaston \& Marmar, 1994) was also considered for this study. It is a self-administered questionnaire designed in two parallel versions for patients and therapists, and it provides an evaluation of four indices in the therapeutic alliance: working capacity of the patient, patient engagement, consensus on the strategy work, and understanding and therapist's commitment. The CALPAS also has a version for evaluating the therapeutic alliance of the group as a whole (Lindgren, Barber, \& Sandhal, 2008). This, like the version for the dual setting (Gaston \& Marmar, 1994), has good levels of internal consistency and seems to be able to predict the positive results determined by the therapy. However, this instrument does not focus on the therapeutic factors that emerge during the group.

We considered the two complementary questionnaires (for the therapists and the patients) for the construction of an FAT.A.S.-G. that provides a version for patients (FAT.A.S.- P.) and a mirror for the therapists (FAT.A.S.-T.).

Finally, the Therapeutic Factors Inventory (TFI; Joyce, MacNair-Semands, Tasca, \& Ogrodniczuk, 2011) consist of 11 scales, each of which is composed of nine items to investigate all the factors originally formulated by Yalom (1995). The scale has a high internal consistency $(\alpha=.84)$ and a good testretest value $(r>.63)$, but the scale's length represents an important limit. The items of the subscale of cohesion (Cohesion Subscale of Therapeutic Factors Inventory) reflect the sense of belonging among the group members and acceptance and cooperation in group experiences. This subscale was taken into account for the construction of the FAT.A.S.-G.

\section{Aim oft he study}

The aim of this study is a preliminary evaluation of factor structure of the FAT.A.S.-G. (Marogna, 2009). A preliminary examination of the factorial structure of the questionnaire version for patients was conducted. In line with previous studies focused on the factorial variables of the group process (Johnson, 2005; Kivlinghan, Multon, \& Brossart, 1996; Sexton, 1993), we hypothesized that the questionnaire structure reflects a smaller number of global dimensions in the group process, rather than the 11 factors theorized by Yalom (1995). 


\section{Method}

\section{Measures}

FAT.A.S.-G.: Construction of the Questionnaire. Referring to the studies by Yalom (1974), Giorgi, Sguazzin, Simon and Tesio (2006), MacKenzie (1981), Gaston and Marmar (1994), and Lese and MacNair-Semands (2000), we developed the FAT.A.S.-G. Questionnaire.
A scientific review was conducted of the theories and tools presented in the literature regarding groups, and from these sources, we developed ex novo 90 items that describe the meaning of therapeutic factors. Preliminary analyzes were conducted to assess the clarity, correspondence, with the definition of the factors, and the redundancy of the 90 items. A final list of 41 items was settled on within the research team, consisting of group psychotherapy clinical practitioners and psy-

Table 1a. Descriptive statistics for each item of questionnaire

\begin{tabular}{|c|c|c|c|c|c|}
\hline & \multirow[b]{2}{*}{ Mean } & \multirow[b]{2}{*}{ DS } & \multicolumn{3}{|c|}{ Stnd. } \\
\hline & & & Asymmetry & Err. & Kurtosis \\
\hline 1. I feel I have the necessary resources to deal with my problems. & 2,20 & 0,9 & 0,09 & 0,19 & $-0,29$ \\
\hline $\begin{array}{l}\text { 2. It gave me relief to know I'm not the only one to have certain problems and } \\
\text { experiences. }\end{array}$ & 2,44 & 1,1 & $-0,42$ & 0,19 & $-0,61$ \\
\hline $\begin{array}{l}\text { 3. I give help by the chance to experience behaviors and attitudes put in place by } \\
\text { other members. }\end{array}$ & 2,33 & 1,1 & $-0,26$ & 0,19 & $-0,55$ \\
\hline 4. In the group I was able to reflect on my way of relating with others. & 2,37 & 1,0 & $-0,34$ & 0,19 & $-0,27$ \\
\hline 5. In the group I experienced support and involvement. & 2,17 & 1,1 & $-0,10$ & 0,19 & $-0,61$ \\
\hline $\begin{array}{l}\text { 6. I find the group suggestions, ideas, information to understand and deal with } \\
\text { my practical difficulties. }\end{array}$ & 2,07 & 1,1 & $-0,05$ & 0,19 & $-0,48$ \\
\hline 7. In the group I can express myself freely. & 2,33 & 1,1 & $-0,19$ & 0,19 & $-0,59$ \\
\hline 8. To be of help to others in the group makes me feel better. & 2,31 & 1,1 & $-0,41$ & 0,19 & $-0,55$ \\
\hline $\begin{array}{l}\text { 9. Discuss what I feel with the members of the group led me to understand the } \\
\text { difficulties I had and that I have with my family. }\end{array}$ & 2,00 & 1,1 & $-0,08$ & 0,19 & $-0,59$ \\
\hline 10. I think the time I'm investing in therapy is useful. & 2,89 & 2,4 & 9,37 & 0,19 & 108,71 \\
\hline 11. I think that within the group there are positive role models to follow. & 1,99 & 1,1 & $-0,1$ & 0,19 & $-0,73$ \\
\hline 12. I feel confident of the effectiveness of treatment as a chance to get better. & 2,43 & 1,0 & $-0,36$ & 0,19 & $-0,25$ \\
\hline $\begin{array}{l}\text { 13. I have a feeling that others do not understand my problems because they are } \\
\text { too specific. }\end{array}$ & 2,53 & 1,2 & $-0,48$ & 0,19 & $-0,71$ \\
\hline 14. I feel that the group recognizes my skills. & 1,94 & 1,0 & 0,12 & 0,19 & $-0,33$ \\
\hline 15. According to the group I saw it with different eyes the episodes of my past. & 1,85 & 1,1 & 0,13 & 0,19 & $-0,61$ \\
\hline $\begin{array}{l}\text { 16. The group enlightened me because others react in a certain way to my behav- } \\
\text { iors. }\end{array}$ & 1,52 & 1,0 & 0,25 & 0,19 & $-0,48$ \\
\hline $\begin{array}{l}\text { 17. Thanks to my contribution in the group I realized that I have the qualities } \\
\text { useful to others. }\end{array}$ & 1,74 & 1,1 & 0,22 & 0,19 & $-0,43$ \\
\hline 18. By attending the group I received advice on how to relate with people. & 1,82 & 1,1 & 0,15 & 0,19 & $-0,50$ \\
\hline 19. I can express what I feel towards the group, feeling that I am accepted. & 2,14 & 1,0 & $-0,19$ & 0,19 & $-0,24$ \\
\hline $\begin{array}{l}\text { 20. The group helps me to understand that they are able to assume the responsi- } \\
\text { bilities of my life, no matter how much I have supported and guided by others. }\end{array}$ & 1,97 & 1,0 & 0,03 & 0,19 & $-0,30$ \\
\hline 21. I feel appreciated and part of the group. & 2,08 & 1,0 & $-0,30$ & 0,19 & $-0,12$ \\
\hline 22. In the group does not feel that it is my job to help others. & 2,42 & 1,3 & $-0,31$ & 0,19 & $-0,91$ \\
\hline 23. The behavior of others is too different from how I behave myself. & 2,44 & 1,2 & $-0,38$ & 0,19 & $-0,72$ \\
\hline $\begin{array}{l}\text { 24. See that the other members of the group have difficulties made me feel less } \\
\text { alone. }\end{array}$ & 2,20 & 1,1 & $-0,37$ & 0,19 & $-0,62$ \\
\hline 25. In the group can reveal sensitive personal information and intimate. & 2,02 & 1,1 & $-0,29$ & 0,19 & $-0,49$ \\
\hline $\begin{array}{l}\text { 26. See and hear the other members make progress thanks to the group was an } \\
\text { encouragement to me. }\end{array}$ & 2,22 & 1,2 & $-0,35$ & 0,19 & $-0,76$ \\
\hline
\end{tabular}


chologists with group psychotherapy research experience. The research group was involved in assessing the level of understanding and meaning of each item.

The final version of the questionnaire consists of 41 items: four items were used for each therapeutic factor, except for Information/Guide factor that is defined by five items to better grasp the construct's complexity. Socialization and Learning Techniques Interpersonal therapeutic factors were merged, even if Yalom differentiates them in terms of input (the socialization techniques) and output (interpersonal learning). The two aspects seem so interconnected that is extremely difficult to split them. In the construction and selection of items, appropriate attention was paid to this subdivision in trying to bring out both sides equally. The participants were asked to answer to each item in a 5-point $\mathrm{Li}$ kert scale (where 0 indicates "not at all" and 4 "very much").

The self-report questionnaire was developed to analyze the therapeutic process, which gives information about how the group develops and changes over time. With the aim of evaluating the process, the questionnaire was designed to be administered at different times, so repeated assessments over time were made in order to capture the dynamic reality that is characterized by constant changes. Two forms of the same questionnaire were developed: one for patients and one for the therapist. The patients' form gives information about the group experience and its therapeutic function, giving to the therapist an overall picture of the group as a whole and the experiences of each patient within the group. The therapist's form is parallel evaluations of the patients and is easily comparable with the other form because it was developed in the same manner. The therapist is asked to answer the same patient questions: what factors are activated in the course of therapy, to what degree, and in what terms?

\section{Sampling}

This study involved 167 participants ( 92 males and 65 females); 52 from groups of people with mental disorders of various kinds (mood, anxiety, psychotic), 55 from groups of drug users, 36 from groups of parents with teenage children with specific problems due to their stage of life, and 24 from experiential groups. Participants' ages ranged between 19 and 81 years $(M=42.09, S D=13.38)$, and they were recruited from mental health centers, family clinics, and psychiatric hospitals for supportive intervention groups of short duration. Specifically, a minimum of five and a maximum of 10 participants

Table 1b. Descriptive statistics for each item of questionnaire

\begin{tabular}{|c|c|c|c|c|c|}
\hline & Mean & DS & Asymmetry & $\begin{array}{l}\text { Stnd. } \\
\text { Err. }\end{array}$ & Kurtosis \\
\hline $\begin{array}{l}\text { 27. The relationship I have with other members of the group made me think } \\
\text { about how my behavior corresponds to a specific reaction of my family. }\end{array}$ & 1,72 & 1,1 & 0,24 & 0,19 & $-0,67$ \\
\hline 28. I do not trust the group and this helps me to express what I feel. & 2,86 & 1,3 & $-0,89$ & 0,19 & $-0,36$ \\
\hline $\begin{array}{l}\text { 29. In therapy, there have been occasions when I have thorough knowledge of } \\
\text { my symptoms. }\end{array}$ & 2,52 & 1,2 & $-0,34$ & 0,19 & $-0,74$ \\
\hline $\begin{array}{l}\text { 30. See what others fail to reveal embarrassing things and benefit from it helped } \\
\text { me to do the same. }\end{array}$ & 1,91 & 1,1 & 0,00 & 0,19 & $-0,65$ \\
\hline $\begin{array}{l}\text { 31. Reliving situations emotionally important within the group made me under- } \\
\text { stand the reasons for certain attitudes and behaviors towards my family. }\end{array}$ & 1,71 & 1,1 & 0,17 & 0,19 & $-0,59$ \\
\hline 32. I think at the end of the group cause concern. & 2,57 & 1,3 & $-0,57$ & 0,19 & $-0,74$ \\
\hline 33. In the group I do not feel helped and supported by others. & 2,69 & 1,2 & $-0,52$ & 0,19 & $-0,70$ \\
\hline 34. In group I understood how it developed my way of relating. & 1,64 & 1,0 & 0,15 & 0,19 & $-0,29$ \\
\hline 35. The therapist gives information about how the group. & 2,36 & 1,1 & $-0,31$ & 0,19 & $-0,45$ \\
\hline $\begin{array}{l}\text { 36. Compare with the other members of the group makes me feel less uncomfor- } \\
\text { table than my problems. }\end{array}$ & 2,28 & 0,9 & $-0,24$ & 0,19 & $-0,11$ \\
\hline 37. The information that I receive in group I are of no use. & 3,10 & 1,1 & $-1,05$ & 0,19 & 0,18 \\
\hline $\begin{array}{l}\text { 38. I learned from the group that the difficult moments are part of the life and } \\
\text { that must be addressed. }\end{array}$ & 2,53 & 1,1 & $-0,51$ & 0,19 & $-0,32$ \\
\hline $\begin{array}{l}\text { 39. I do not trust others and rejecting them feel as emotionally distant and } \\
\text { closed. }\end{array}$ & 2,99 & 1,2 & $-0,98$ & 0,19 & 0,00 \\
\hline 40. What others tell about my reactions help me to better understand them. & 1,93 & 1,0 & 0,00 & 0,19 & $-0,32$ \\
\hline 41. The group does not help me and I would like to suspend therapy. & 3,13 & 1,3 & $-1,30$ & 0,19 & 0,42 \\
\hline
\end{tabular}


composed each group and each intervention was carried out in minimum of eight meetings and a maximum of 12 meetings.

The questionnaire was administered in three phases of treatment: at the beginning $(t 1)$, in the middle phase ( $t 2)$, and at the end ( $t 3)$. Dropout cases in the sample were previously identified and eliminated and only participants who filled out the questionnaire in the three phases were considered for the analysis. The questionnaire was carried out in anonymous way at the end of the sessions.

\section{Data Analysis}

Statistical package SPSS 17.0 for statistical and descriptive analysis was used for the analysis of principal components with eigenvalue $>1$ and for the analysis of scree-test function. The extracted components have been rotated according to the Varimax method in order to obtain a more clearly readable structure (Kaiser, 1958). For each subject of the sample, the total score of the questionnaire was taken into account, which is the sum of the scores for each item, considering it an expression of the overall process that occurs in the group. Cronbach's Alpha was used as a measure of internal consistency of each of the factors that emerged from the exploratory factor analysis. Subsequently correlation between factors was examined.

\section{Results}

Descriptive statistics of each items are presented in Table 1.

Bartlett's test of sphericity was significant $(\chi 2=$ $3.494,59, \mathrm{df}=820, p<.000)$, and the KMO's index showed a good sampling adequacy, with a value near to $0.90(\mathrm{KMO}=0.895)$. These results led to proceeding with a factorial analysis.

The choice of the number of factors is deduced from the analysis of the correlation matrix and the scree plot of eigenvalues; furthermore, the number of factors was been identified on the basis of previous studies that suggested the existence of few components underlying the therapeutic factors (Stone, Lewis, \& Beck, 1994). From the Exploratory Factor Analysis, a two-factor solution was the result. The final solution accounted for $42.09 \%$ of the total variance. In particular, the first component extracted accounted for $31.15 \%$ of the variance and the second for $10.94 \%$. All the items showed a correlation coefficient of > 0.30 , and they were taken into account for the interpretation of the components with the extracted components rotating with the function Varimax (Kaiser, 1958): each item shows a saturation of $>.30$ in one of the two components greater than this value, and no item were deleted. In a few cases in which an item correlated with both factors, the highest saturation in the factor was considered (Table 2).
Table 2. Two-factor rotated factor solution measured at Time 1

\begin{tabular}{|c|c|c|}
\hline & Component 1 & Component 2 \\
\hline Item 1 & 0,449 & \\
\hline Item 2 & 0,435 & \\
\hline Item 3 & & 0,564 \\
\hline Item 4 & 0,654 & \\
\hline Item 5 & 0,701 & \\
\hline Item 6 & 0,756 & \\
\hline Item 7 & & 0,572 \\
\hline Item 8 & 0,642 & \\
\hline Item 9 & 0,663 & \\
\hline Item 10 & 0,641 & \\
\hline Item 11 & 0,515 & \\
\hline Item 12 & 0,662 & \\
\hline Item 13 & & 0,718 \\
\hline Item 14 & 0,705 & \\
\hline Item 15 & 0,651 & \\
\hline Item 16 & 0,701 & \\
\hline Item 17 & 0,704 & \\
\hline Item 18 & 0,662 & \\
\hline Item 19 & 0,559 & \\
\hline Item 20 & 0,743 & \\
\hline Item 21 & 0,617 & \\
\hline Item 22 & & 0,588 \\
\hline Item 23 & & 0,602 \\
\hline Item 24 & 0,721 & \\
\hline Item 25 & 0,488 & \\
\hline Item 26 & 0,807 & \\
\hline Item 27 & 0,701 & \\
\hline Item 28 & & 0,703 \\
\hline Item 29 & & 0,428 \\
\hline Item 30 & 0,687 & \\
\hline Item 31 & 0,762 & \\
\hline Item 32 & & 0,437 \\
\hline Item 33 & & 0,733 \\
\hline Item 34 & 0,662 & \\
\hline Item 35 & 0,396 & \\
\hline Item 36 & 0,442 & \\
\hline Item 37 & & 0,821 \\
\hline Item 38 & 0,674 & \\
\hline Item 39 & & 0,831 \\
\hline Item 40 & 0,337 & \\
\hline Item 41 & & 0,659 \\
\hline
\end{tabular}


The first component, "Interdependence", was composed of 31 items. The second component, "Group as Object-Self", was composed of 10 items. Also, it was considered that the total score of items, called "Global Factor", represented the complex therapeutic work that is born and grows progressively with the succession of the sessions and with the interaction between patients, between patients and therapist, and between patients and the group as a whole and that has as its objective the growth of adaptive capacity and improving the quality of life of individual patients.

Cronbach's coefficient alpha for the two components and for the global factor was calculated as "Global Factor" with a reliability of .93, and the elimination of one item at a time (function "Deleted") does not lead to any modification of this value, showing that no item weakens the internal consistency of this dimension. "Interdependence" presented an alpha value of .93 and, in this case, no item weakens the internal consistency of this dimension. "Group as Object-Self" had an alpha value of .85. Subsequently, using the relationship between the extracted components and "Global Factor", the Index of Pearson Correlation was calculated (Table 3).

Table 3. Pearson correlations between Interdependence, Group as Object-Self, and Factor Global

Factor Global Interdependence

$\begin{array}{lcc}\text { Group as Object-Self } & , 556^{* *} & , 297^{* *} \\ & .000 & : 000 \\ & , 958^{* *} & \\ \text { Interdependence } & .000 & \end{array}$

${ }^{* *} \mathrm{p}<0,01$

The correlation matrix presented in Table 3 shows a significant correlation between "Interdependence" and "Group as Object-Self" ( $\mathrm{r}=.29)$, between "Group as Object-Self" and "Global Factor" $(\mathrm{r}=.55)$, and, finally, between "Interdependence" and "Global Factor" $(r=.95)$. These results show that interconnectedness, relatedness, or interdependence are very important dimensions of what is occurring within the group and are very connected with the whole group process.

\section{Discussion}

The international literature presented several factorial studies on the variables of the process group that highlighted the presence of a small set of global dimensions (Johnson, 2005; Kivlinghan, Multon, \&
Brossart, 1996; Sexton, 1993). In line with this hypothesis, we have identified two components underlying the 11 therapeutic factors theorized by Yalom (1975), as "Interdependence" and "Group as Object-Self". These two components accounted for $42.09 \%$ the amount of the total variance.

The first component, "Interdependence" (Lewin, 1951), represents the main constructs that are featured in a clinical/psychotherapy group setting. It is an intersubjective dimension that is defined by the connection between bodies, feelings, needs, and psychic worlds (Harwood \& Pines, 1998). The central aspect that emerges from the content of these statements about this first component extracted is precisely the utility that the person can draw from the comparison, by reciprocity, of the exchanges and then the possible recognition within the group becomes the vehicle for the personal development, understanding of self and the surrounding world, and the growth of self-esteem (Jacobson, Dobson, Truax, \& Addis, 1996). Within the group, each participant can find satisfaction for the need to behave and to be recognized by the others for own personal authenticity. This group experience, fortifying awareness, is able to improve individual and social growth, responsibility, and openness to others. These relational movements are the results of the development of a safe emotional climate; commitment and participation, based on sharing; and comparison and interdependence, all aimed at strengthening self-esteem and the identity of each person. The ability to deal with others in a group allows for the recognition of diversity as a resource and as an opportunity to adopt new ways of thinking and acting. This understanding level implies an important meta-learning that recognizes that the other is other than himself/herself because it is different from him/her and involves a continuous decentralization that help people to look through the eyes of other (Foulkes, 1975).

The group is a resource for the growth of the individual and for the improvement of his/her adaptation levels. The meanings that participants give to the group, relationships, and reciprocity are related to the nature of intervention, support and belief, and the homogeneity of the sample. The relational dynamic that is activated in the group involves relationships between the patients and the therapist and among patients as a whole, and they allow for specificity in the therapeutic group at the connection level. In this regards, the component "Interdependence" well represents the multiplicity of relationships within the group from which comes the possibility, for each member, to understand the nature of his or her psychological problems as well as the responses of others and not only by the actions of the therapist. The interdependence then is connected with the function of group reverie, which contains and reworks the scattered and incompre- 
hensible elements, understanding, and the discovery of new meanings (Corrao, 1981).

The group can be the means by which each participant reaches an insight, which as stated by Bloch, Crouch and Reibstein (1981), is a complex concept with multidimensional implications with two different processes: one that reflects the subject's understanding of his or her personal psychological process, and the other is an interpersonal process that refers to the nature of the relations that the person establishes with others. Therefore, the interdependence helps individuals to have a greater awareness about the effect of their thoughts and their actions on the others.

The second component, "Group as Object-Self " (Kohut, 1984; Blacks, 1995), identifies the change process that each individual can develop within the group, and it is clear from a clinical point of view but complex to operationalize. In this work, to operationalize it, we referred to the difference occurring between the scores of therapeutic factors and the clinical observations of the core themes that emerge in the course of treatment. The level of confidencecloseness and distance Self/Others are the core of the attitude that a person uses to face and find a place in the group. Therefore, this component indicates that the individual can move from passivity to action by the others behaviors that represent model examples. Individuals learn to trust and to get help from others and, at the same time, develop an ability to participate, exchange, and express themselves within the group. The confidence attitude towards each other and towards the group, whether or not the recognition is of the utility of the group, regulates the behavior, the participation, and the opportunity to learn from and in the group experience.

The active role of the person in the group is a very important aspect to emphasize. This gradual transition from the hold back and feel more distant to the progressive approach to others and the liability for actions are the prerequisites for the effective development of the first component and then a deeper work of the person. This could be substantiated by its significant correlation (.37) that links the two components and it is indicative of a mutual influence between them: if one increases, the other also increases.

Both of these extracted components are also significantly associated with the Global Factor, showing a contribution to determining the therapeutic process put in place by the group. The Global Factor is the sum of the first and second components extracted, and it represents the set of the role that each person assumes in the group, as all that a person can learn from the relationship and mutual exchange with the other.

The present work represents an initial evaluation of the effectiveness of the questionnaire in capturing the progress of therapeutic factors over time as a possibility for understanding the mechanisms of actions of the therapeutic process from the quantitative point of view of clinical research.

The questionnaire appears to be an initial brief measure with adequate psychometric properties that can be an effective method to help clinicians and researchers to identify the perception of the therapeutic process among the group participants. It has important methodological limitations, including the lack of external criteria with which to compare the results of the questionnaire. In this first phase, only the perceptions of patients were taken into account. In the future, it will be necessary to expand the number of participants and the types of participants' problems and diagnoses of the subjects included in the sample as well as verify the results and compare them with other available measures to analyze concurrent and predictive validity.

Future research should focus on confirmatory factor analysis and assess if the two forms of the questionnaire allow the therapists to compare their valuations of the perception of the therapeutic process with that of their patients. Finally, this study only analyzed the data collected in the first administration $(\mathrm{t} 1)$ of the questionnaire, so additional studies should consider the data collected during $t 2$ and $t 3$ to evaluate the evolution of therapeutic process of each group and to detect if the same factorial structure that occurred in this study is maintained during that time.

\section{References}

Beck, A. P., \& Lewis, C. M. (2000). The process of group psychotherapy: Systems for Analyzing Change. Washington: American Psychological Association.

Bednar, R. L., \& Kaul, T.J. (1994). Experiential Group research: Can the cannon fire? In Bergin S.L., Garfield, Handbook of Psychotherapy and Behaviour Change (4th ed., 631-663). Ney York: Wiley.

Bion, W. R. (1972). Apprendere dall'esperienza. Roma: Armando Editore.

Bion, W. R. (1977). Esperienze nei gruppi. Roma: Armando Editore.

Bloch, S., \& Crouch, E. (1985). Therapeutic Factors in Group Psychotherapy. Oxford: Oxford University Press.

Bloch, S., Crouch, E., \& Reibstein, J. (1981). Therapeutic factors in psychotherapy: a review. Archives of General Psychiatry, 38 (5), 519-526.

Brown, T.A., \& Barlow, D.H. (1995). Long-term out come in cognitive-behavioral treatment of panic disorder: Clinical predictors and alternative strategies for assessment. Journal of Consulting and Clinical Psychology, 63, 754-765.

Burlingame, G. M., MacKenzie, R. K., \& Strauss, B. (2004). Small group treatment: Evidence for effectiveness and mechanisms of change. In Lambert, M., ed. Handbook of Psychotherapy and Behavior Change, 5, 647-696. New York: Wiley.

Butler, T., \& Fuhriman, A. (1983). Curative factors in group therapy: A review of the recent literature. Small Group Behavior, 14, 131-142.

Corrao, F. (1981). Struttura poliadica e funzione gamma. In Corrao, T., (a cura di), Orme, Vol. II. Milano: Raffaello 
Cortina.

Corsini, R., \& Rosenberg, B. (1955). Mechanism of group psychotherapy: Processes and dynamics. Journal of $A b$ normal and Social Psychology, 51, 406-411.

Costantini, A., Picardi, A., Podrasky, E., Lunetta, S., Ferraresi, G., \& Balbi, A. (2002). Questionario sul clima di gruppo: validazione di una misura di processo per le psicoterapie di gruppo. Rivista di Psichiatria, 37, 15-19.

Dierick, P., \& Lietaer, G. (2008). Client perception of therapeutic factors in group psychotherapy and growth group: an empirically-based hierarchical model. International Journal of Group Psychotherapy, 58 (2), 203-230.

Di Riso, D., Colli, A., Chessa, D., Marogna, C., Condino, V., Lis, A., Lingiardi, V., \& Mannarini, S. (2011). A supportive approach in psychodynamic - Oriented psychotherapy. An empirically supported single case study. Research in Psychotherapy: Psychopathology, Process and Outcome, 14 (1), 49-89.

Ettin, M. (1999). Foundations and applications of group psychotherapy: A sphere of influence. London: Jessica Kingsley Publishers Ltd.

Fonagy, P., Gergely, G., Jurist, E. L., \& Target, M. (2002). Affect Regulation, Mentalization, and the Development of the Self. London: Other Press. Tr. it. (2005). Regolazione affettiva, mentalizzazione e sviluppo del Sé. Milano: Raffaello Cortina.

Foulkes, S. H. (1975). La psicoterapia gruppoanalitica. Roma: Astrolabio.

Gaston, L., \& Marmar, C. R. (1994). The California Psychotherapy Alliance Scales. In Horvath, A.O., Greenberg, L. S. (Eds.), The Working Alliance: theory, research and practice, 85-108. New York: Wiley \& Sons.

Giorgi, I., Sguazzin, C., Baiardi, P., Simone, A., \& Tesio, L. (2006). Uno strumento per la valutazione dell'attività terapeutica di gruppo (GrEThA - Q). Giornale italiano di medicina del lavoro ed ergonomia, 28, Supplemento di Psicologia 1, 61-70.

Harwood, I. N. H., \& Pines, M. (1998). Esperienze del Sé in gruppo. Roma: Edizione Borla.

Jacobson, N. S., Dobson, K. S., Truax, P. A., \& Addis, M. E. (1996). A component analysis of

cognitive-behavioral treatment for depression. Journal of Consulting and Clinical Psychology,

64, 295-304.

Johnson, J. E., Burlingame, G. M., Olsen, J. A., Davies, D. R., \& Gleave, R.L. (2005). Group climate, cohesion, alliance and empathy in group psychotherapy: multilevel structural equation models. Journal of Counseling Psychology, $52,3,310-321$.

Joyce, A. S., MacNair-Semands, R., Tasca, G. A., \& Ogrodniczuk, J. S. (2011). Factor structure and validity of the Therapeutic Factors Inventory - Short Form. Group Dynamics: Theory, Research, and Practice, 15 (3), 201-219.

Kaiser, H. F. (1958). The application of electronic computers to factor analysis. Educational and Psychological Measurement, 20, 141-151.

Kirchmann, H., Mestel, R., Schreiber-Willnow, K., Mattke, D., Seidler, K., Daudert, E., Nickel, R., Papenhausen, R., Eckert, J., \& Strauss, B. (2009). Associations among attachment characteristics, patients' assessment of therapeutic factors, and treatment outcome following inpatient psychodynamic group psychotherapy. Psychotherapy Research, 19 (2), 234-248.
Kivlighan, D. M., \& Goldfine, D. (1991). Endorsement of therapeutic factors as a function of stage of group development and participant interpersonal attitudes. Journal of Counseling Psychology, 38 (2), 150-158.

Kivlighan, D. M., Kivlighan, M.C. (2004). Counselor intentions in individual and group treatment. Journal of Counseling Psychology, 51, 347-353.

Kohut, H. (1984). La cura psicoanalitica. Torino: Bollati Boringhieri.

Lese, K., MacNair-Semands, R. (2000). The Therapeutic Factors Inventory: development of a scale. Group, 24 (4), 303-317.

Lewin, K. (1951). Field theory in social science: selected theoretical papers. New York: Harper \& Row. Tr. It. (1982). Teoria e sperimentazione in psicologia sociale. Bologna: Il Mulino.

Lindgren, A., Barber, J. P., Sandahl, C. (2008). Alliance to the Group-as-a-Whole as a Predictor of Outcome in Psycho-dynamic Group Therapy. International Journal of Group Psychotherapy, 58 (2), 163-184.

Lis, A., Sambin, M., Ferruzza, E., Marogna, C., Rocco, D., \& Salcuni, S. (2010). Filoni di ricerca in psicoterapia nella Facoltà di Psicologia dell'Università di Padova. Research in Psychotherapy: Psychopathology, Process and Outcome, 13 (2), 168-190.

MacKenzie, K. R. (1981). Measurement of group climate. International Journal of Group Psychotherapy, 31, 287295.

MacNair-Semands, R., Ogrodniczuk, J., \& Joyce, A. (2010). Structure and initial validation of a short form of the Therapeutic Factors Inventory. International Journal of Group Psychotherapy, 60 (2), 245-281.

Marogna, C. (2009). FAT.A.S.-G. Manuale per la siglatura. Manoscritto non pubblicato.

Neri, C. (1995). Gruppo. Roma: Borla.

Orange, D. M., Atwood, G. E., \& Storolow, R. D. (1999). Intersoggettività e lavoro clinico. Il contestualismo nella pratica psicoanalitica. Milano: Raffaello Cortina.

Parloff, M. B. (1988). Stato attuale della ricerca sui risultati della psicoterapia. Psicoterapia e scienze umane, 22 (3), 9-39.

Rohrbaugh, M., \& Bartels, B. D. (1975). Participants' perception of "curative factors" in therapy and growth group. Small Group Behavior, 6, 430-456.

Roy, V., Turcotte, D., Montminy, L., \& Lindsay, J. (2005). Therapeutic factors at the beginning of the intervention process in group for men who batter. Small Group Research, 36, 106-133.

Sexton, H. (1993). Exploring a psychotherapeutic change sequence: Relating process to intersessional and posttreatment outcome. Journal of Consulting and Clinical psychology, 61, 128-136.

Stern, N. D. (2005). Il momento presente. In psicoterapia e nella vita quotidiana. Milano: Raffaello Cortina.

Yalom, I. D., (1995). Teoria e pratica della psicoterapia di gruppo. Torino: Bollati Boringhieri.

Yalom, I. D., Leszcz, M. (2005). The Theory and practice of Group Psychotherapy -5th Edition Tr. It. Teoria e pratica della psicoterapia di gruppo. Torino: Bollati Boringhieri.

Submitted December 11, 2013

Revision received September 13, 2014

Accepted January 28, 2015 